\title{
Microstructure and Microwave Absorption Properties of Y-Substituted Ni-Zn Ferrites
}

\author{
Na Chen ${ }^{1 *}$, Mingyuan $\mathrm{Gu}^{2}$ \\ ${ }^{1}$ Department of Pharmaceutical Science \& Technology, College of Chemistry and Biology, \\ Donghua University, Shanghai, China \\ ${ }^{2}$ State Key Laboratory of MMCs, Shanghai Jiaotong University, Shanghai, China \\ Email: *n.chen78@gmail.com
}

Received February 28, 2012; revised April 28, 2012; accepted May 24, 2012

\begin{abstract}
The Yttrium ions substituted Ni-Zn ferrites powders were prepared using a sol-gel technique. The crystal structure, magnetic properties and microwave absorption properties of the Ni-Zn ferrites powders were studied by X-ray diffraction, vibrating sample magnetometer and vector network analyzer. The results show that the microwave absorption properties of the Ni-Zn ferrites can be improved effectively with the substitution of $\mathrm{Y}$ ions. The minimum reflection loss of the Yttrium ions substituted Ni-Zn powder reaches $-34.8 \mathrm{~dB}$, with the $-20 \mathrm{~dB}$ bandwidth over $2 \mathrm{GHz}$. The Yttrium substitution can improve microwave absorption properties of $\mathrm{Ni}-\mathrm{Zn}$ ferrite due to smaller grain dimension and the higher specific magnetization
\end{abstract}

Keywords: Nick-Zinc Ferrite; Sol-Gel Preparation; Magnetic Properties; Microwave Absorption

\section{Introduction}

Due to the fast development in information and communication technology, the environmental pollution from non-ionizing microwave irradiation has increased, and there are many researches on various materials which can be used as microwave absorbing and shielding materials. Nickel-zinc ferrites are a well-known class of technologically important ferrite used as microwave absorbing materials [1-3]. Microwave absorption properties are highly dependent on processing parameters and chemical composition. These factors can greatly influence the crystal size, magnetic properties, complex magnetic permeability $\left(\mu_{r}\right)$ and complex permittivity $\left(\varepsilon_{r}\right)$ [4-7]. The Ni-Zn ferrite is a well-known mixed inverse spinel, whose unitary cell is represented by the formula $\left(\mathrm{Zn}_{\mathrm{x}} \mathrm{Fe}_{1-\mathrm{x}}\right)\left[\mathrm{Ni}_{1-\mathrm{x}} \mathrm{Fe}_{1+\mathrm{x}}\right] \mathrm{O}_{4}$ [8]. The addition of impurities induces changes in the defect structure and texture of the crystal [9], creating significant modifications in the magnetic and electrical properties of these materials. However, the synthesis route also plays a crucial role, so that samples of comparable crystallite size prepared by different processes show different electrical and magnetic properties. There are many methods to synthesize $\mathrm{Ni}-\mathrm{Zn}$ ferrite, such as co-precipitation [5], thermal plasma [10], hydrolysis [11] etc.

The influences of rare earth (RE) substitution on the

*Corresponding author. structural and magnetic properties of Ni-Zn ferrites have been studied $[12,13]$. The partial substitution of $\mathrm{Fe}^{3+}$ with a small amount of RE ions increases the electrical resistivity and the relative loss factor, whereas it slightly decreases Curie temperature, and the ferrites were made by the reaction combustion synthesis method and sintered at $1200^{\circ} \mathrm{C}$ [12]. However, few studies have been done on the microwave absorption properties of these rare earth substitution $\mathrm{Ni}-\mathrm{Zn}$ ferrites.

According pre-experiment, among different $\mathrm{Ni}-\mathrm{Zn}$ ratios in the $\mathrm{Ni}_{\mathrm{x}} \mathrm{Zn}_{1-\mathrm{x}} \mathrm{Fe}_{2} \mathrm{O}_{4}$, the $\mathrm{Ni}_{0.7} \mathrm{Zn}_{0.3} \mathrm{Fe}_{2} \mathrm{O}_{4}$ possess of excellent magnetic properties. In this work, the $\mathrm{Y}$-substituted $\mathrm{Ni}_{0.7} \mathrm{Zn}_{0.3} \mathrm{Fe}_{2} \mathrm{O}_{4}$ ferrites were prepared by sol-gel followed by a citrate-nitrate auto-combustion process in order to obtain the substitution ferrites at a relatively lower temperature; The influences of $\mathrm{Y}^{3+}$ substitution on the microstructure, magnetic properties and microwave absorption properties were investigated. Yttrium was selected as doped element because of its comparable radius with $\mathrm{Fe}$.

\section{Experimental}

\subsection{Synthesis}

The $\mathrm{Ni}_{0.7} \mathrm{Zn}_{0.3} \mathrm{Y}_{\mathrm{x}} \mathrm{Fe}_{2-\mathrm{x}} \mathrm{O}_{4}(\mathrm{x}=0,0.2)$ ferrite powders were prepared using sol-gel technique followed by an autocombustion process. The stoichiometric amounts of $\mathrm{Ni}\left(\mathrm{NO}_{3}\right)_{2}, \mathrm{Zn}\left(\mathrm{NO}_{3}\right)_{2}, \mathrm{Fe}\left(\mathrm{NO}_{3}\right)_{3} \cdot 9 \mathrm{H}_{2} \mathrm{O}$ and $\mathrm{Y}\left(\mathrm{NO}_{3}\right)_{3} \cdot 6 \mathrm{H}_{2} \mathrm{O}$ 
were dissolved in deionized water followed by the addition of citric acid. The solution was slowly evaporated at $353 \mathrm{~K}$. The dry gel obtained after dried in $383 \mathrm{~K}$ was ignited in air and burned into dentritic and brittle powders. They were finally calcined at $1173 \mathrm{~K}$ for one hour.

\subsection{Characterization}

The crystal structure of the materials were determined with X-ray diffraction (XRD) carried out on a BrukerAXS D8 Advanced diffractometer with $\mathrm{Cu} \mathrm{K}$ radiation in the $2 \theta$ range from 10 to 80 with steps of 0.02 , measurement time $2 \mathrm{~s}$, measurement temperature $25^{\circ} \mathrm{C}$, standard: Si powder. The magnetic properties including of specific saturation magnetization $(\sigma s)$ and coercivity $(\mathrm{Hc})$ of powders were measured with a vibrating sample magnetometer (VSM) model 155 (made in ED\&G PRINCETON APPLIED RESEARCH U.S.A,) at a maximum applied field of $15 \mathrm{KOe}$ at room temperature.

The specimens for microwave absorption test are prepared by mixing the $\mathrm{Ni}_{0.7} \mathrm{Zn}_{0.3} \mathrm{Y}_{\mathrm{x}} \mathrm{Fe}_{2-\mathrm{x}} \mathrm{O}_{4}$ ferrite powders with $30 \mathrm{wt} \%$ paraffin wax and made into a toroidal shape ( $\varphi_{\text {out }}: 7.03 \mathrm{~mm}, \varphi_{\text {in }}: 3.00 \mathrm{~mm}$ ). The relative permeability and permittivity values of the specimens were measured in the 2 - $18 \mathrm{GHz}$ using a network analyzer (Agilent Technologies 8722ES). The reflection loss (RL) curves were calculated from the relative permeability and permittivity at the given frequency and absorber thickness, according to the following equations [14]:

$$
\begin{aligned}
& Z_{\text {in }}=Z_{0}\left(\mu_{r} \varepsilon_{r}\right)^{1 / 2} \tanh \left\{j(2 \pi f t / c)\left(\mu_{r} \varepsilon_{r}\right)^{1 / 2}\right\} \\
& \operatorname{RL}(\mathrm{dB})=20 \log \left|\left(Z_{\text {in }}-Z_{0}\right) /\left(Z_{\text {in }}+Z_{0}\right)\right|
\end{aligned}
$$

where $f$ is the frequency of microwave, $t$ is the thickness of absorber, $c$ is the velocity of light, $Z_{0}$ is the impedance for free space, and $Z_{i n}$ is the input impedance of absorber. The RL values of $-20 \mathrm{~dB}$ is comparable to the $99 \%$ of microwave absorption according to Equations (1) and (2), and thus "RL $<-20 \mathrm{~dB}$ " is considered as an attractive potential microwave application.

\section{Results and Discussions}

\subsection{Crystal Structure Analysis}

For comparison purpose, the XRD patterns of original $\mathrm{Ni}-\mathrm{Zn}$ ferrite is given in Figure 1(a), and the XRD patterns of Y-substituted Ni-Zn ferrite is shown in Figure 1(b). All the specimens were calcined at $1173 \mathrm{~K}$ for $1 \mathrm{~h}$ in air. The crystal structure of $\mathrm{Ni}_{0.7} \mathrm{Zn}_{0.3} \mathrm{Y}_{0.2} \mathrm{Fe}_{1.8} \mathrm{O}_{4}$ determined from Figure 1(b) is spinel ferrite; no characteristic peaks for other phases are detected. It can be deduced that the $\mathrm{Y}$ are completely doped into the Ni-Zn ferrite. The cell parameters of the ferrites were refined using least square refinement methods. Average crystallite size
(D) of all the samples is calculated using the Debyescherrer equation [15] given by

$$
D=\frac{0.94 \lambda}{\beta \cos \theta}
$$

where $\lambda$ is the wavelength of the $\mathrm{X}$-ray radiation used and $\beta$ is the full width at half intensity maximum (FWHM) of the most intense peak and $\theta$ is the diffraction angle of the most intense peak (311). The results are given in Table 1. It can be seen that the change of the lattice parameter after the doping of $\mathrm{Y}$ is minor, and the crystallite size of the substituted Ni-Zn ferrites is much smaller. The magnetic properties were also shown in Table 1. It can be seen that the specific saturation magnetization $\left(\sigma_{s}\right)$ increased and the coercivity $\left(H_{c}\right)$ decreased with the substitution of Y. It is thus expected that the substitutedNiZn ferrite might possess different microwave absorbing properties when compared with the NiZn ferrites.

There are two possible existence state of $\mathrm{Y}$ in the Ni-Zn ferrites: Some of $\mathrm{Y}^{3+}$ entered the lattice and substituted the $\mathrm{Fe}^{3+}$; other $\mathrm{Y}$ diffused to the grain boundary during the sintering process. $\mathrm{Y}^{3+}$ ion entering the lattice can result in the increasing of the lattice parameter because of $\mathrm{Y}^{3+}$ ion's larger radius $(0.73 \AA)$ than $\mathrm{Fe}^{3+}(0.67$ $\AA)$; But $\mathrm{Y}$ congregating at grain boundary will reduce lattice parameter due to the vacancies left in the $\mathrm{Ni}-\mathrm{Zn}$ lattice; As a combination of the two effect described above, no significant overall lattice parameterchange can be observed. As for the crystallite sizereducing, two kind

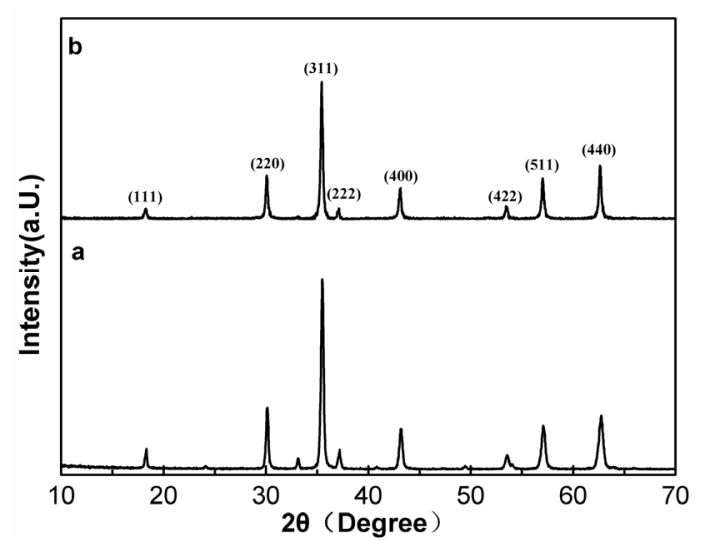

Figure 1. XRD patterns of $\mathrm{Ni}_{0.7} \mathrm{Zn}_{0.3} \mathrm{Y}_{\mathrm{x}} \mathrm{Fe}_{2-\mathrm{x}} \mathrm{O}_{4}$ ferrites ((a) $\mathrm{x}$ $=0$; (b) $\mathrm{x}=0.2$ ).

Table 1. Lattice parameters, grain sizes and magnetic properties of $\mathrm{Ni}_{0.7} \mathrm{Zn}_{0.3} \mathrm{Y}_{\mathrm{x}} \mathrm{Fe}_{2-\mathrm{x}} \mathrm{O}_{\mathbf{4}}$ ferrites.

\begin{tabular}{ccccc}
\hline \multirow{2}{*}{$\begin{array}{c}\text { Substitution } \\
\text { amount } \mathrm{x}\end{array}$} & $\begin{array}{c}\text { Lattice } \\
\text { parameters }(\AA)\end{array}$ & $\begin{array}{c}\text { Crystallite } \\
\text { size }(\mathrm{nm})\end{array}$ & \multicolumn{2}{c}{$\begin{array}{c}\text { Magnetic } \\
\text { Properties }\end{array}$} \\
\cline { 2 - 2 } & $\mathrm{a}$ & & $\sigma_{\mathrm{s}}(\mathrm{emu} / \mathrm{g})$ & $\mathrm{H}_{\mathrm{c}}(\mathrm{Oe})$ \\
\hline 0 & $8.382 \pm 0.003$ & 76.4 & 59.32 & 130 \\
0.2 & $8.380 \pm 0.002$ & 39.7 & 64.85 & 110 \\
\hline
\end{tabular}


of Y existence state both can constrain the growth of the grain: The $\mathrm{Y}$ substitution in the lattice will induce lattice distortion, internal stress caused by this distortion hinders the growth of grains; If Y diffused to the grain boundaries, that will also restrain the grain growth by lower down the grain mobility; That explains why the crystallite size of the substituted $\mathrm{Ni}-\mathrm{Zn}$ ferrite is much smaller than un-doped ferrites. Similar results have also been reported in the literature $[12,13]$.

\subsection{Dielectric and Magnetic Parameters}

Figure 2(a) shows the real part $\left(\varepsilon^{\prime}\right)$ and the imaginary part $\left(\varepsilon^{\prime \prime}\right)$ of the relative complex permittivity for ferrites within the frequency of $2-18 \mathrm{GHz}$. It showed that the Y substitution increase the relative permittivity in the $\mathrm{GHz}$ frequency range, which is consistent with the result of literature [9]. The probable reason is the substitution induce more electric dipole, so the imaginary part of the relative complex permittivity $\left(\varepsilon^{\prime \prime}\right)$ increase. The real part $\left(\mu^{\prime}\right)$ and the imaginary part $\left(\mu^{\prime \prime}\right)$ of the relative complex permeability are plotted as a function of frequency in Figures 2(b) and 2(c). With the substitution of the $\mathrm{Y}$, the $\mu^{\prime \prime}$ values will increase, it can be explained from the change of the magnetic properties. For the single wall anisotropic particles, there is

$$
\begin{aligned}
& \mu^{\prime \prime}=M_{s} / 2 \mu_{0} H_{A} \alpha \\
& H_{A}=2 K_{1} / M_{s} \\
& \mu_{r}^{\prime \prime}=M_{s}^{2} / 4 \mu_{0} K_{1} \alpha \propto \sigma_{s}^{2} / H_{c} \propto M_{s}^{2} / H_{c}
\end{aligned}
$$

where $M_{s}$ is saturation magnetization, $\alpha$ is Gilbert damping coefficient, $\mu_{0}$ is permeability of vacuum, $H_{\alpha}$ is anisotropy field, $K_{1}$ is the anisotropy constant. So with the increase of specific saturation magnetization $\left(\sigma_{s}\right)$ and the decrease of the coercivity, the $\mu^{\prime \prime}$ values increase.

\subsection{Microwave Absorbing Properties.}

Figure 3 shows a typical relationship between $\mathrm{RL}$ and frequency for the $\mathrm{Ni}_{0.7} \mathrm{Zn}_{0.3} \mathrm{Fe}_{2} \mathrm{O}_{4}$ ferrite (Figure 3(a)) and $\mathrm{Ni}_{0.7} \mathrm{Zn}_{0.3} \mathrm{Y}_{\mathrm{x}} \mathrm{Fe}_{2-\mathrm{x}} \mathrm{O}_{4}$ ferrite (Figure 3(b)) with the absorber thickness of $1.5-3.5 \mathrm{~mm}$. The minimum reflection loss is equivalent to the occurrence of minimal reflection of microwave power. The minimum reflection loss of the $\mathrm{Ni}_{0.7} \mathrm{Zn}_{0.3} \mathrm{Fe}_{2} \mathrm{O}_{4}$ ferrite was only $-24.5 \mathrm{~dB}$ at $8.5 \mathrm{GHz}$ with a thickness of $2.5 \mathrm{~mm}$ (Figure 3(a)) However, for Y doped ferrite, the RL values less than $-20 \mathrm{~dB}$ were recorded in the $6.2-8.9 \mathrm{GHZ}$ with the absorber thickness of $1.5-3.5 \mathrm{~mm}$. In particular, a minimum RL of $-34.8 \mathrm{~dB}$ was obtained at $8 \mathrm{GHz}$ with a thickness of $2.5 \mathrm{~mm}$ and its bandwidth less than $-20 \mathrm{~dB}$ is $2.1 \mathrm{GHz}$ (Figure 4(b)). It can be seen that the microwave absorption properties are improved comparing with non-
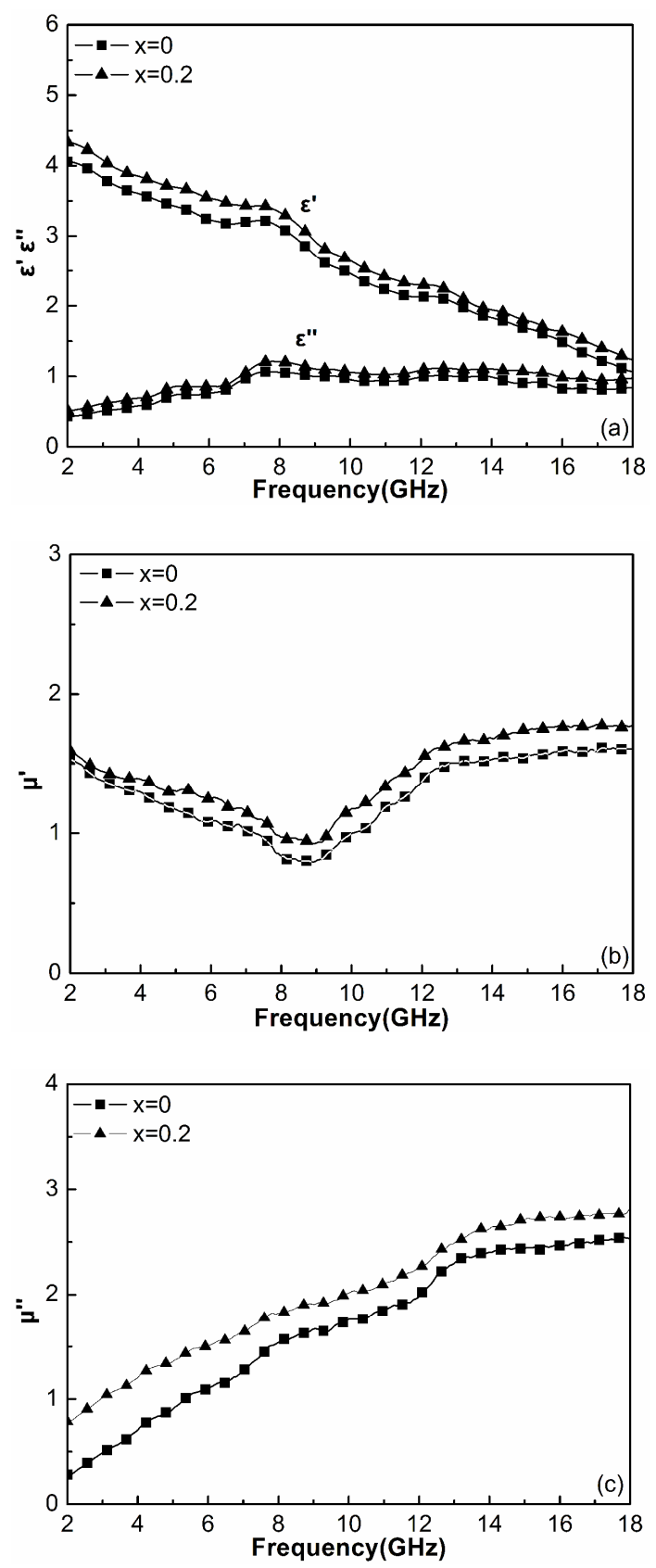

Figure 2. Frequency dependences of relative permittivity $\varepsilon$ (a), real part $\mu^{\prime}$ (b), and imaginary part $\mu^{\prime \prime}$ (c) of relative permeability for the $\mathrm{Y}$-substituted ferrites.

substituted ferrites. The frequency at which the RL value reaches minimum moved to lower frequency because of the substituted, which is related to the change of coercivity $\left(H_{c}\right)$.

The improvement of microwave absorbing properties of the ferrites might can be explained as following: Firstly, the substitution made the crystallite sizesmaller and deformed the lattice, which will induce repetitious reflection when the microwave spreading in the ferrites, so more energy will be absorbed; Secondly, the substitu- 

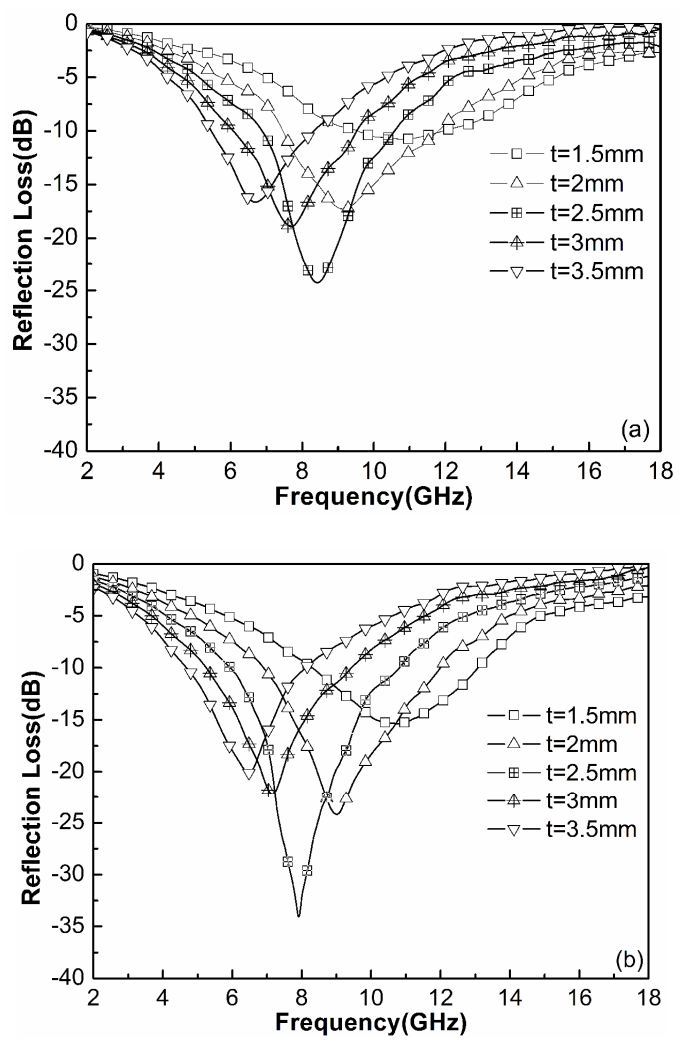

Figure 3. Frequency dependence of $\mathrm{RL}$ for $\mathrm{Ni}_{0.7} \mathrm{Zn}_{0.3} \mathrm{Y}_{\mathrm{x}} \mathrm{Fe}_{2-\mathrm{x}} \mathrm{O}_{4}$ ferrite $(x=0$, (a); $x=0.2$, (b)) at different thickness.

tion can influence the microwave absorption performance by increasing the imaginary part of the relative complex permittivity $\left(\varepsilon^{\prime \prime}\right)$ and permittivity $\left(\mu^{\prime \prime}\right)$. So, the $\mathrm{Y}$ substituted NiZn ferrite got much better microwave absorption properties.

\section{Conclusion}

The $\mathrm{Ni}_{0.7} \mathrm{Zn}_{0.3} \mathrm{Y}_{\mathrm{x}} \mathrm{Fe}_{2-\mathrm{x}} \mathrm{O}_{4}$ powders were prepared using sol-gel technique. The crystallite size of the

$\mathrm{Ni}_{0.7} \mathrm{Zn}_{0.3} \mathrm{Y}_{0.2} \mathrm{Fe}_{1.8} \mathrm{O}_{4}$ is smaller than that of the $\mathrm{Ni}_{0.7} \mathrm{Zn}_{0.3} \mathrm{Fe}_{2} \mathrm{O}_{4}$. The specific saturation magnetization $\left(\sigma_{s}\right)$ increased and the coercivity $\left(H_{c}\right)$ decreased with the substitution of $\mathrm{Y}$. The imaginary part of permeability and permittivity value of substituted ferrites both increased comparing with that of $\mathrm{Ni}_{0.7} \mathrm{Zn}_{0.3} \mathrm{Fe}_{2} \mathrm{O}_{4}$. The Y substitutions make the minimum reflection loss frequency shift to a lower frequency and the frequency range of $\mathrm{RL}<$ $-20 \mathrm{~dB}$ expand comparing with that of $\mathrm{Ni}_{0.7} \mathrm{Zn}_{0.3} \mathrm{Fe}_{2} \mathrm{O}_{4}$ ferrite. The improvement of absorption performance may be attributed to the relative permeability and permittivity change and the grain refinement induced by the $\mathrm{Y}$ substitution.

\section{REFERENCES}

[1] C. H. Peng, C. C Hwang, J. Wan, J. S. Tsai and S. Y.
Chen, "Microwave-Absorbing Characteristics for the Composites of Thermal-Plastic Polyurethane (TPU)Bonded NiZn-Ferrites Prepared by Combustion Synthesis Method," Materials Science and Engineering B, Vol. 117, No. 1, 2005, pp. 27-36. doi:10.1016/j.mseb.2004.10.022

[2] H. Montiel, G. Alvarez, M. P. Gutierrez, R. Zamorano and R. Valenzuela, "Microwave Absorption in Ni-Zn Ferrites through the Curie Transition," Journal of Alloys and Compounds, Vol. 369, No. 1-2, 2004, pp. 141-143. doi:10.1016/j.jallcom.2003.09.074

[3] A. N. Yusoff, M. H. Abdullah, S. H. Ahmad, S. F. Jusoh, A. A. Mansor and S. A. A. hamid, "Electromagnetic and Absorption Properties of Some Microwave Absorbers," Journal of Applied Physics, Vol. 92, No. 2, 2002, pp. 876-882. doi:10.1063/1.1489092

[4] T. Tsutaoka, "Frequency Dispersion of Complex Permeability in Mn-Zn and Ni-Zn Spinel Ferrites and Their Composite Materials," Journal of Applied Physics, Vol. 93, No. 5, 2003, pp. 2789-2796. doi:10.1063/1.1542651

[5] H. Gul, W. Ahmed and A. Maqsood, "Electrical and Magnetic Characterization of nanocrystalline Ni-Zn Ferrite Synthesis by Co-Precipitation Route," Journal of Magnetism and Magnetic Materials, Vol. 320, No. 3-4, 2008, pp. 270-275. doi:10.1016/j.jmmm.2007.05.032

[6] Y. Hwang, "Microwave Absorbing Properties of NiZnFerrite Synthesized from Waste Iron Oxide Catalyst," Materials Letters, Vol. 60, No. 27, 2006, pp. 3277-3280. doi:10.1016/j.matlet.2006.03.010

[7] A. Verma, A. K. Saxena and D. C. Dube, "Microwave Permittivity and Permeability of Ferrite-Polymer Thick Films," Journal of Magnetism and. Magnetic Materials, Vol. 263, No. 1-2, 2003, pp. 228-234. doi:10.1016/S0304-8853(02)01569-X

[8] R. C. O'Handley, "Modern Magnetic Materials-Principles and Applications," Wiley, USA, 2000.

[9] A. M. El-Sayed, "Electrical Conductivity of Nickel-Zinc and Cr Substituted Nickel-Zinc Ferrites," Materials Chemistry and Physics, Vol. 82, No. 3, 2003, pp. 583-587. doi:10.1016/S0254-0584(03)00319-5

[10] A. B Nawale, N. S. Kanhe, K. R. Patil, S. V. Bhoraskar, V. L. Mathe and A. K. Das, "Magnetic Properties of Thermal Plasma Synthesized Nanocrystalline Nickel Ferrite $\left(\mathrm{NiFe}_{2} \mathrm{O}_{4}\right)$," Journal of Alloys and Compounds, Vol. 509, No. 12, 2011, pp. 4404-4413. doi:10.1016/j.jallcom.2011.01.057

[11] R. Valenzuela, F. Herbst and S. Ammar, "Ferromagnetic Resonance in Ni-Zn Ferrite Nanoparticles in Different Aggregation States," Journal of Magnetism and Magnetic Materials, 2012, In Press. doi:10.1016/j.jmmm.2012.02.051

[12] G. Sun, J. Li, J. Sun and X. Yang, "The Influences of $\mathrm{Zn}^{2+}$ and Some Rare-Earth Ions on the Magnetic Properties of Nickel-Zinc Ferrites," Journal of Magnetism and. Magnetic Materials, Vol. 281, No. 2-3, 2004, pp. 173-177. doi:10.1016/j.jmmm.2004.04.099

[13] S. E. Jacobo, W. G. Fano and A. C. Razzitte, "The Effect of Rare Earth Substitution on the Magnetic Properties of $\mathrm{Ni}_{0.5} \mathrm{Zn}_{0.5} \mathrm{M}_{\mathrm{x}} \mathrm{Fe}_{2-\mathrm{x}} \mathrm{O}_{4}$ (M: Rare Earth)," Physica B, Vol. 
320, No. 1-4, 2002, pp. 261-263. doi:10.1016/S0921-4526(02)00706-8

[14] H. M. Musal Jr. and H. T. Hahn, "Thin-Layer Electromagnetic Absorber Design," IEEE Transactions on Magnetics, Vol. 25, No.5, 1989, pp. 3851-3853. doi: $10.1109 / 20.42454$

[15] C. Upadhyay, "Cation Distribution in Nanosized Ni-Zn Ferrites," Journal of Applied Physics, Vol. 95, 2004, pp. 5746-5746. doi:10.1063/1.1699501 